\title{
Assessing the Impact of Weather on Traffic Intensity
}

\author{
Mario CoOls, Elke MoOns, AND GeERT Wets \\ Transportation Research Institute, Hasselt University, Diepenbeek, Belgium
}

(Manuscript received 5 March 2009, in final form 23 October 2009)

\begin{abstract}
This paper focuses on the effect of weather conditions on daily traffic intensities (the number of cars passing a specific segment of a road). The main objective is to examination whether or not weather conditions uniformly alter daily traffic intensities in Belgium, or in other words whether or not road usage on a particular location determines the size of the impacts of various weather conditions. This general examination is a contribution that allows policymakers to assess the appropriateness of countrywide versus local traffic management strategies. In addition, a secondary goal of this paper is to validate findings in international literature within a Belgian context. To achieve these goals, the paper analyzes the effects of weather conditions on both upstream (toward a specific location) and downstream (away from a specific location) traffic intensities at three traffic count locations typified by a different road usage. Perhaps the most interesting results of this study for policymakers are the heterogeneity of the weather effects between different traffic count locations, and the homogeneity of the weather effects on upstream and downstream traffic at specific locations. The results also indicate that snowfall, rainfall, and wind speed diminish traffic intensity, and high temperatures increase traffic intensity. Further generalizations of the findings might be possible by studying weather impacts on local roads and by shifting the focus of research toward travel behavior.
\end{abstract}

\section{Introduction}

\section{a. Background}

A clear insight into how weather conditions influence traffic is essential for policymakers. This is underlined by policy issues that are often related to adverse weather events such as increased fuel consumption, economic losses due to traffic delays, and higher traffic counts. Day-to-day weather conditions such as fog and precipitation can reduce travel, for instance when drivers postpone or cancel discretionary activities, but can also have an increased effect on traffic when travel modes are shifted from slow modes (walking, cycling) toward motorized vehicles (Hranac et al. 2006). At the network level, adverse weather events increase the uncertainty in system performance, resulting, for instance, in a network capacity reduction ranging from $10 \%$ to $20 \%$ in heavy rain (De Palma and Rochat 1999).

Corresponding author address: Mario Cools, Transportation Research Institute, Hasselt University, Wetenschapspark 5 bus 6 , 3590 Diepenbeek, Belgium.

E-mail:mario.cools@uhasselt.be
Figure 1 displays the conceptual framework of the interplay between weather conditions, traffic intensity (the number of cars crossing/passing a specific segment of a road, also referred to as traffic flow), traffic speed, and road safety (Koetse and Rietveld 2007). Take as an example heavy rain conditions during which drivers might reduce their travel speed. This action could reduce road capacities and corresponding traffic intensities. There might also be a direct decrease in traffic intensity resulting from people cancelling their trips. The resulting reduction in traffic intensity and traffic speed could decrease the severity of accidents, but slippery roads on the other hand could increase the frequency of accidents. This example illustrates the long recognized proposition that road accidents and traffic intensities are the consequence of an interaction between behavioral, environmental, and technological factors. A change in any of these factors could prevent an accident from occurring (Edwards 1996; Levine et al. 1995).

The rise of advanced traffic management systems (ATMS) provides transportation agencies the opportunity to implement traffic management strategies that could limit weather-related side effects on traffic operations (Zhang et al. 2005). A solid understanding of 


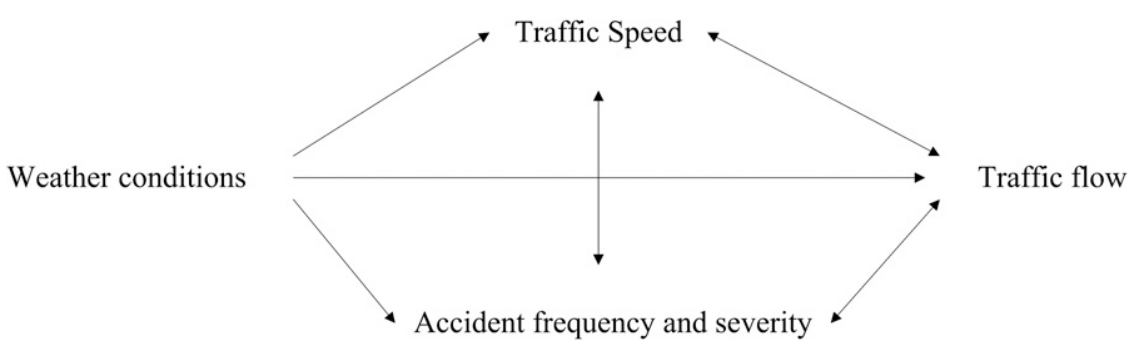

FIG. 1. Relationship between weather, road safety, traffic speed, and traffic intensity.

the impact of various weather conditions on roadside crash frequency and traffic intensity serves as a good knowledge base for developing these strategies (Shankar et al. 2004; Smith et al. 2004).

The assessment of weather impacts on traffic intensity (the daily number of vehicles passing a specific location) is of significant value to travel-demand modelers. Khattak and De Palma (1997) reported that adverse weather conditions cause important changes in travel decisions: mode changes, changes in departure time, and diversions to alternate routes were reported as the most prevalent behavioral adaptations.

The investigation of weather effects on traffic intensity is also important from a road safety point of view, because traffic intensity, commonly used as a proxy variable for exposure (the degree of participation in traffic) in traffic safety literature, is noted as the first and primary determinant of traffic safety (Van den Bossche et al. 2005). Injury accidents are nearly proportionally related with exposure (Fridstrøm et al. 1995), evidencing the strong relationship between traffic intensity conditions and the likelihood of traffic accidents (Golob et al. 2004).

Summarizing, weather events can affect two predominant traffic domains: traffic intensity or in a broader sense traffic demand and traffic safety (Maze et al. 2006). Traffic intensities are the revealed traffic pattern on the road network, and traffic demand covers also the underlying demand for activity participation and demand for different transportation options. This paper focuses on the impact of weather events on the first, predominant traffic domain, namely traffic intensity. The main objective is a general examination of whether or not weather conditions uniformly alter daily traffic intensities in Belgium, or in other words whether or not the road usage (the main purpose for people traveling on this road, i.e., commuting or leisure) on a particular location determines the size of the effects of various weather conditions. This general examination is a contribution that allows policymakers to assess the appropriateness of countrywide versus local traffic management strategies. In addition, a secondary goal of this paper is to validate findings in the international literature within a Belgian context.
The remainder of this introductory section will address specific weather variables that influence traffic intensities and traffic demand. Section 2 will describe the data, and Section 3, the methodology. Finally, the paper will present the results and elaborate on their transport policy relevant interpretation. Some general conclusions will be formulated and avenues for further research indicated.

\section{b. Influence of weather on traffic intensities and traffic demand}

Weather can affect traffic intensities and traffic demand in different ways, including diversions of trips to other modes or other paths, or even cancellations of trips (Maze et al. 2006). Bos (2001) indicated that in the Netherlands heavy rain is associated with a smaller number of cyclists, and mild winters and warm summers have a strong impact on bicycle use. A similar relationship was found by Nankervis (1999) who examined the effect of both (short term) weather conditions and (long term) seasonal variation patterns on bicycle commuting patterns among students in the temperate climate of Melbourne, Australia. He found that cycle commuting was affected by long-term, climatic conditions as well as daily weather conditions. Guo et al. (2007) reported that temperature, rain, snow, and wind all influence transit ridership of the Chicago Transit Authority: good weather increases ridership, while bad weather has a diminishing effect. Guo et al. (2007) also stress that not only the transit ridership is influenced by weather, but also vehicle running times (time it takes to complete the assigned route) and dwell times (time spent in getting on or off the public transit vehicle) are affected, as well as the cost of operation. In Brussels, Belgium, on the other hand, the transit agency reported higher levels of transit ridership during adverse weather (Khattak and De Palma 1997).

From various studies on the effect of rain, snow, and fog on traffic operations, it has become clear that adverse weather can significantly reduce not only capacity but also operating speeds on roadways, resulting in congestion and productivity loss (Agarwal et al. 2006; Datla and Sharma 2008). When the effect of precipitation on traffic 


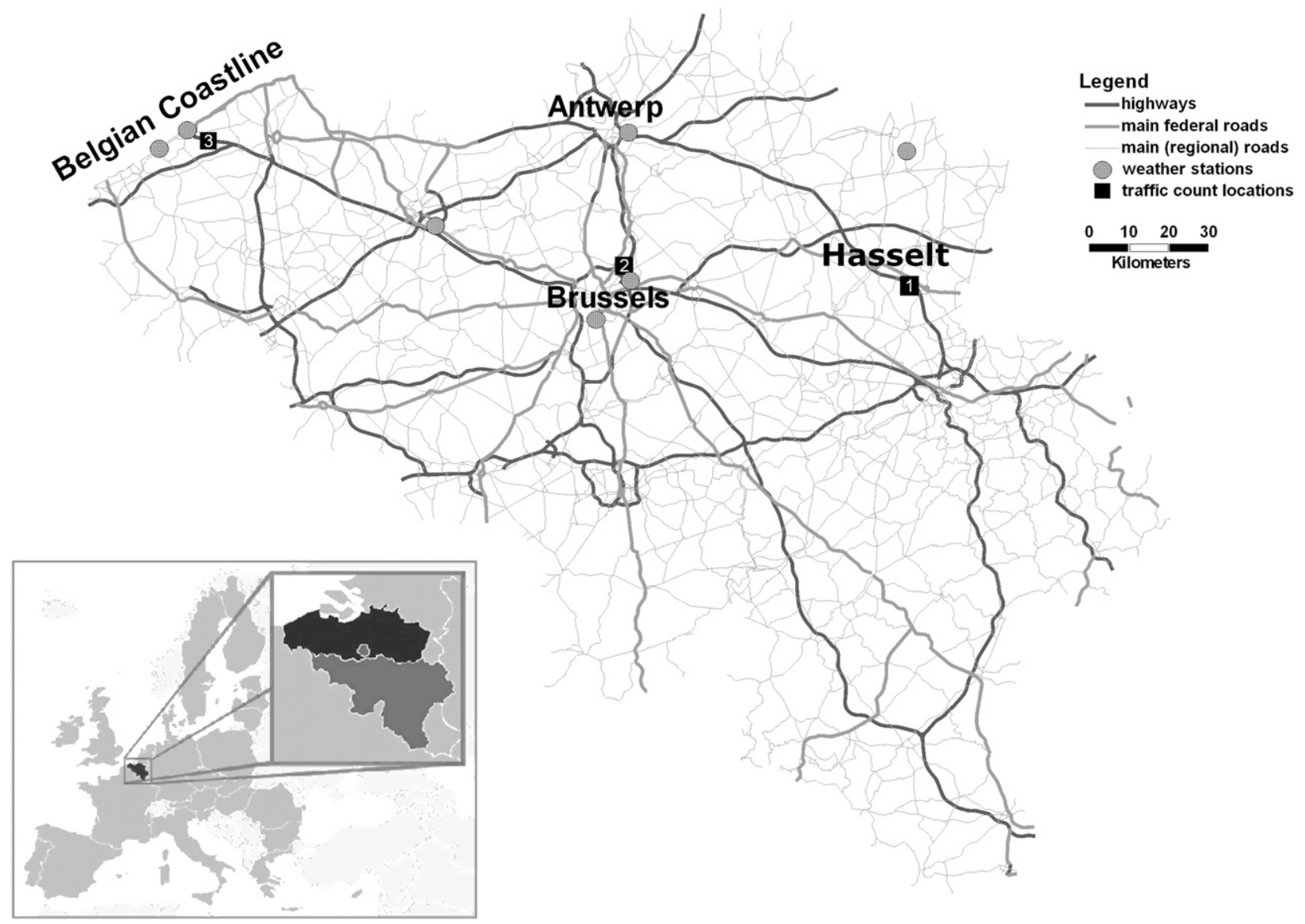

FIG. 2. Representation of the traffic count locations and weather stations under study.

operations is explored, almost all studies indicate that speed and capacity are negatively influenced (Stern et al. 2003; Unrau and Andrey 2006). Hanbali and Kuemmel (1993) found traffic volume reductions on highways away from the major urban centers in the United States ranging from $7 \%$ to $56 \%$ depending on the intensity of the snowfall. Maze et al. (2006) found comparable reductions in traffic volume on Interstate 35 in northern rural Iowa ranging from $7 \%$ to $80 \%$ during snowstorms. In contrast, during rainstorms traffic volumes were reduced by less than 5\%. According to Smith et al. (2004), who analyzed the effect of precipitation on traffic intensity in Hampton Roads, Virginia, highway capacity is reduced by a range from $4 \%$ to $10 \%$ during light rain (intensity of 0.01 $6.35 \mathrm{~mm} \mathrm{~h}^{-1}$ ) and a range from $25 \%$ to $30 \%$ during heavy rain (intensity higher than $6.35 \mathrm{~mm} \mathrm{~h}^{-1}$ ).

When the focus is on highway speeds, Ibrahim and Hall (1994) found reductions in speed of, respectively, 2 and $3 \mathrm{~km} \mathrm{~h}^{-1}$ during light rain and light snow, and decreases in speed of 5-10 $\mathrm{km} \mathrm{h}^{-1}$ during heavy rain and $38-50 \mathrm{~km} \mathrm{~h}^{-1}$ during heavy snow. The reductions tend to be larger for larger precipitation amounts (Keay and
Simmonds 2005). Other factors influencing traffic intensity are visibility (fog), wind speed, sunshine hours, and temperature, the latter two associated with slight increases in traffic activity (Hassan and Barker 1999).

\section{Data}

To assess the impact of weather conditions on traffic intensity, and in particular to test the hypothesis that the road usage on a particular location determines the size of the effects of weather conditions on traffic intensities, the upstream (toward a specific location) and downstream (away from a specific location) traffic of three traffic count locations (represented by black squares in Fig. 2) were considered. Weather conditions at these traffic count locations were approximated by weather conditions recorded in the closest weather stations (represented by gray circles in Fig. 2).

\section{a. Dependent variables: Traffic intensity data}

The traffic intensity data originate from minute-byminute data coming from single inductive loop detectors, 
collected in 2003 and 2004 by the Vlaams Verkeerscentrum (Flemish Traffic Control Center). Every minute, the loop detectors generate four statistics: the number of cars that have driven by, the number of trucks that have driven by, the occupancy of the detector (the percentage of time that the detector is "occupied" by vehicles), and the timemean speed of all vehicles (Maerivoet 2006). Adding up the number of cars and trucks for all lanes in a specific direction yields a total traffic count for each minute. The aggregation on a daily basis of all 1440 minute-long total traffic counts then results in a single daily traffic intensity measure. Note that this aggregation on a daily level also filters away the noise caused by random fluctuations because of potential inaccuracies of single loop detector counts. For a general discussion about the quality of traffic counts derived from single loop detectors the reader is referred to Chen et al. (2003) and Weijermars and Van Berkum (2006).

As indicated earlier, upstream and downstream traffic intensity of three traffic count locations (displayed as black numbered squares in Fig. 2) are investigated in this study. The first location is a traffic count location measuring upstream and downstream highway traffic from Hasselt, a provincial city with a population of about 70000 people. The highway where these upstream and downstream traffic counts are measured is characterized by two lanes in each direction, used both for commuting and leisure traffic. The second traffic count location is situated on one of the entranceways of Brussels, the capital of the European Union, and thus is an important location in terms of job opportunities. At the location of the traffic counts, the highway consists of three lanes in each direction, predominantly used by commuters. The third location is on one of the access highways (three lanes in each direction) to the Belgian seashore, and thus more intensively used by leisure traffic. Note that the speed limit on all these locations was equal to $120 \mathrm{~km} \mathrm{~h}^{-1}$.

\section{b. Independent variables}

\section{1) WEATHER DATA}

Data concerning weather events were recorded by the Royal Meteorological Institute of Belgium (KMI). These data originate from Automatic Weather Stations (AWS) equipped with a present weather sensor (PWS). In addition to the PWS, these AWS are also equipped with a ceilometer, an anemometer, a temperature sensor, a hygrometer, and rain gauges. Weather at the relevant traffic count locations was approximated by the conditions recorded at the nearest (available) weather stations. The following variables were included in the analysis: daily precipitation (expressed in $1 / 10 \mathrm{~mm}$; all 24-hourly measurements from rain gauges are aggregated to a daily level), conditions of hail, snow, and thunderstorm [a dummy variable indicating the presence of the weather event during the day under study was created for each of these weather events; the weather types were derived from the PWS, and enriched with data from the Surveillance et Alerte Foudre par Interférométrie Radioélectrique (SAFIR) lightning detection system], average and maximum cloudiness (expressed in eighths; the average and maximum of all 24-hourly measurements was calculated; the degree of cloudiness was derived from the ceilometer), minimum, maximum, and average temperature (expressed in ${ }^{\circ} \mathrm{C}$; the minimum, maximum, and average from all 24-hourly averages were tabulated), maximum hourly wind speed (expressed in $\mathrm{m} \mathrm{s}^{-1}$; the maximum of all 24-hourly averages was taken), sunshine duration (expressed in minutes; all 24-hourly durations were added up), and duration of diminished visibility due to fog (a dummy variable was created indicating that for the day under study for at least a few minutes the visibility was less than $200 \mathrm{~m}$ ).

In general, Belgium has a temperate maritime climate influenced by the North Sea and Atlantic Ocean, with cool summers and moderate winters. There is little variation in climate from region to region, although the marine influences are less inland. Rainfall is distributed throughout the year with a dryer period from April to September. Summary information about the meteorological conditions for the years 2003 and 2004 is provided in Table 1.

\section{2) TEMPORAL EFFECTS}

In addition to the different weather conditions that will be used to (partially) explain the variability in traffic counts, it is also necessary to incorporate temporal effects. Cools et al. (2007) found that day-of-week effects and holiday effects contribute significantly to differences in daily traffic intensity. A first holiday dummy variable was created for the following holidays: Christmas vacation, spring half-term, Easter vacation, Labor Day, Ascension Day, Whit Monday, vacation of the construction industry (3 weeks, starting the second Monday of July), Our Blessed Lady Ascension, fall break (including All Saints' Day and All Soul's Day), and finally Remembrance Day. It should be noted that for all these holidays, the adjacent weekends were considered to be a holiday. Similarly, for holidays occurring on a Tuesday or Thursday, respectively, the Monday and weekend before and the Friday and weekend after were also defined as a holiday. A second holiday dummy variable was created for the summer holidays (excluding holidays considered for the first dummy variable). Thus, for normal days both dummy variables were coded zero. 
TABLE 1. Meteorological conditions in 2003-04. Values are calculated over all 731 days and averaged over all locations $(n=4386)$.

\begin{tabular}{|c|c|c|c|c|}
\hline Parameter of the weather conditions & Mean & Std dev & Min & Max \\
\hline Average maximum wind speed $\left(\mathrm{m} \mathrm{s}^{-1}\right)$ & 6.5 & 2.9 & 1 & 22 \\
\hline Average minimum temperature $\left({ }^{\circ} \mathrm{C}\right)$ & 6.7 & 5.9 & -13.5 & 22.3 \\
\hline Average mean temperature $\left({ }^{\circ} \mathrm{C}\right)$ & 10.8 & 6.5 & -8.3 & 27.8 \\
\hline Average maximum temperature $\left({ }^{\circ} \mathrm{C}\right)$ & 14.8 & 7.5 & -4.0 & 37.1 \\
\hline Average sunshine duration (min day ${ }^{-1}$ ) & 307.2 & 262.1 & 0 & 935 \\
\hline Average cloudiness (eights) & 4.7 & 2.0 & 0 & 8 \\
\hline Average precipitation $\left(1 / 10 \mathrm{~mm} \mathrm{day}^{-1}\right)$ & 18.8 & 42.5 & 0 & 369 \\
\hline Parameter of the weather conditions & 2003 & & 2004 & \\
\hline Number of days with precipitation (year) ${ }^{-1}$ & 149.3 & & 195.7 & \\
\hline Number of days with hail (year) ${ }^{-1}$ & 7.0 & & 11.7 & \\
\hline Number of days with snow (year) ${ }^{-1}$ & 14.3 & & 22.0 & \\
\hline Number of days with thunderstorm $\left(\right.$ year) ${ }^{-1}$ & 17.7 & & 27.7 & \\
\hline Number of days with reduced visibility (year) ${ }^{-1}$ & 9.7 & & 14.7 & \\
\hline
\end{tabular}

Next to these holiday effects, day-of-week effects were also taken into account in this study. As there are 7 days in a week, the first 6 days (Monday until Saturday) were each represented by a dummy, equal to 1 for the days they represent and 0 elsewhere. For the reference day (Sunday), all six dummies were coded 0 .

\section{Methodology}

To develop an understanding of the effects of weather on traffic intensity, some basic descriptive statistics are provided. For the continuous variables the Spearman rank correlation between traffic intensity and the weather variables is calculated. Unlike the traditional Pearson product-moment correlation, the Spearman rank correlation is a nonparametric technique, robust for deviations from normality (Cohen and Cohen 1983). For the categorical variables the group means are provided.

The main modeling approach implemented in this study is the classical linear regression approach. To accommodate for the risk of erroneous model interpretation, caused by autocorrelation (consecutive traffic counts being highly correlated) and heteroskedasticity (the variance of the residuals being dependent on the value of the dependent variable), Newey-West heteroskedasticity and autocorrelation consistent (HAC) covariance matrices are used for the estimation process [Eq. (A1)].

To ensure that all parameter estimates are stable and reliable, the models should be checked for multicollinearity. In the presence of multicollinearity (high correlation between explanatory variables) the effect of a single explanatory variable cannot be isolated, as the regression coefficients are quite uninformative and confidence intervals very wide. Thus, the individual estimated coefficients should be interpreted with caution, since only imprecise information can be derived from the regression coefficients (Van den Bossche et al. 2004). Variance inflation factors (VIF) are used to assess the level of multicollinearity. VIFs measure how much the variances of the computed regression coefficients are inflated as compared to when the predictor variables are not linearly related. The largest VIF value among all predictor variables is used as an indicator of the severity of multicollinearity. A maximum VIF value exceeding 10 indicates that the stability and reliability of the parameter estimates are questionable (Neter et al. 1996).

\section{Results}

\section{a. Validation of findings in international literature within Belgian context}

\section{1) DiRECTION OF THE WEATHER EFFECTS}

A first indication of the direction of the weather effects is given by the sign of the Spearman rank correlations (Table 2) and by the group means of the different categorical weather variables (Table 3). Bad weather conditions such as precipitation, cloudiness and wind speed are negatively correlated with traffic intensity, while good weather conditions such as temperature and sunshine duration are positively correlated. When the group means of the different categorical weather indicators are compared, ambiguity is found in the direction of hail, fog, and thunderstorm effects: on some locations traffic intensity increases in the presence of these weather conditions, on other locations it decreases. In contrast, the impact of snow is univocal: snow decreases the traffic intensity on all traffic count locations. 
TABLE 2. Spearman rank correlations between traffic intensity and continuous predictors.

\begin{tabular}{|c|c|c|c|c|c|c|}
\hline Weather condition & $\begin{array}{c}\text { Down } \\
\text { Hasselt }\end{array}$ & $\begin{array}{c}\text { Up } \\
\text { Hasselt }\end{array}$ & $\begin{array}{c}\text { Down } \\
\text { Brussels }\end{array}$ & $\begin{array}{c}\text { Up } \\
\text { Brussels }\end{array}$ & $\begin{array}{c}\text { Down } \\
\text { Seashore }\end{array}$ & $\begin{array}{c}\text { Up } \\
\text { Seashore }\end{array}$ \\
\hline Cloudiness (mean) & $-0.15^{*}$ & $-0.18^{*}$ & $-0.09 *$ & $-0.10 *$ & $-0.37 *$ & $-0.33^{*}$ \\
\hline Cloudiness (max) & $-0.17^{*}$ & $-0.20 *$ & $-0.09 *$ & $-0.10^{*}$ & $-0.34 *$ & $-0.29 *$ \\
\hline Precipitation & $-0.10 *$ & $-0.13 *$ & $-0.14 *$ & $-0.12^{*}$ & $-0.26^{*}$ & $-0.25 *$ \\
\hline Temperature (mean) & $0.17 *$ & $0.23 *$ & 0.02 & 0.04 & $0.56^{*}$ & $0.52 *$ \\
\hline Temperature $(\max )$ & $0.20 *$ & $0.27 *$ & 0.05 & 0.07 & $0.61 *$ & $0.57 *$ \\
\hline Temperature (min) & $0.13^{*}$ & $0.18^{*}$ & -0.01 & 0.01 & $0.45^{*}$ & $0.42 *$ \\
\hline Wind speed (max) & -0.06 & $-0.09 *$ & $-0.11 *$ & $-0.09 *$ & $-0.26^{*}$ & $-0.25^{*}$ \\
\hline Sunshine duration & $0.15^{*}$ & $0.20 *$ & $0.11 *$ & $0.13^{*}$ & $0.45^{*}$ & $0.42 *$ \\
\hline
\end{tabular}

* Indicates $p$ value $<0.05, n=731$.

A more thorough estimation of the direction of weather effects is obtained by the heteroskedasticity and autocorrelation consistent linear regression models. Estimates for the significant variables that were used in the final location-specific models, their corresponding standard errors, and significance levels are displayed in Table 4. The VIFs (all smaller than 10) assure that the parameter estimates are stable and reliable. The temporal effects (day-of-week effects and holiday effects) are omitted from this table, since this paper focuses mainly on assessing the impact of weather conditions on traffic intensity and because Cools et al. (2007) already reported on the impact of temporal effects. The estimated weather effects are consistent with international literature addressing the impact of weather conditions on traffic intensity (Datla and Sharma 2008; Kyte et al. 2001; Maze et al. 2006): rainfall, snowfall, and wind speed significantly decrease traffic volumes, while temperature has a noticeable increasing effect.

Summarizing, one can conclude that snowfall, precipitation, cloudiness, and wind speed clearly cause traffic intensity to decrease, while temperature and hail increase traffic volumes. Note that although snowfall and rain decrease traffic intensity, hail has the opposite effect. The decrease caused by snowfall and rain may be explained by the diminished capacity of the highway network, caused by a reduction in speed, while the increased intensity due to hail might be attributed to the shift toward the car as a mode of travel under unfavorable weather conditions. Finally, there is also some ev- idence that reduced visibility due to fog and longer duration of sunshine increases traffic intensity.

\section{2) Magnitude of THE WeAther EFFECTS}

In addition to direction, it is also important to assess the magnitude of weather effects on traffic. An initial insight is obtained by looking at the Spearman rank correlations (Table 2). The highest correlations with traffic intensity are maximum temperature and maximum cloudiness and amount of precipitation. Most interesting are the considerably larger correlations of weather conditions at the seashore traffic count location. This suggests that weather conditions have a greater impact on leisure-related traffic than on commuting traffic.

A comprehensive model was developed to quantify the influence of weather conditions on traffic intensity. To accommodate differences in magnitude of the traffic volume between the six traffic count locations (e.g., magnitude of the traffic volume of downstream traffic in Brussels is almost 3 times the magnitude of the traffic volume of downstream traffic in the seashore area), the percentage of traffic volumes relative to their locationspecific mean was modeled instead of the absolute numbers. To obtain a parsimonious model, and based on the homogeneity observed in the location-specific models, upstream and downstream traffic locations were combined to estimate interaction effects between weather conditions and traffic count location. Estimates for the weather conditions and corresponding significance tests of

TABLE 3. Average change in traffic intensity due to presence of weather condition (2003-04). Here $n=731$, changes are calculated relative to all other conditions, and values between parentheses indicate the occurrence of the weather condition.

\begin{tabular}{|c|c|c|c|c|c|c|}
\hline Weather condition & $\begin{array}{c}\text { Down } \\
\text { Hasselt }\end{array}$ & $\begin{array}{c}\text { Up } \\
\text { Hasselt }\end{array}$ & $\begin{array}{c}\text { Down } \\
\text { Brussels }\end{array}$ & $\begin{array}{c}\text { Up } \\
\text { Brussels }\end{array}$ & $\begin{array}{c}\text { Down } \\
\text { Seashore }\end{array}$ & $\begin{array}{c}\text { Up } \\
\text { Seashore }\end{array}$ \\
\hline Hail & $2.58 \%(21)$ & $1.61 \%(21)$ & $6.91 \%(22)$ & $6.72 \%(22)$ & $-10.72 \%(13)$ & $-11.38 \%(13)$ \\
\hline Thunderstorm & $3.61 \%(57)$ & $2.81 \%(57)$ & $-2.54 \%(51)$ & $-1.64 \%(51)$ & $3.73 \%(28)$ & $4.53 \%(28)$ \\
\hline Snow & $-6.69 \%(48)$ & $-7.26 \%(48)$ & $-4.29 \%(39)$ & $-5.83 \%(39)$ & $-14.33 \%(22)$ & $-15.54 \%(22)$ \\
\hline Reduced visibility (fog) & $-3.99 \%(28)$ & $-2.56 \%(28)$ & $-6.17 \%(23)$ & $-7.44 \%(23)$ & $3.87 \%(22)$ & $3.46 \%(22)$ \\
\hline
\end{tabular}


TABLE 4. Parameter estimates (HAC) for the location-specific models.

\begin{tabular}{|c|c|c|c|c|c|c|}
\hline Weather condition & $\begin{array}{l}\text { Down } \\
\text { Hasselt }\end{array}$ & $\begin{array}{c}\text { Up } \\
\text { Hasselt }\end{array}$ & $\begin{array}{c}\text { Down } \\
\text { Brussels }\end{array}$ & $\begin{array}{c}\text { Up } \\
\text { Brussels }\end{array}$ & $\begin{array}{c}\text { Down } \\
\text { Seashore }\end{array}$ & $\begin{array}{c}\text { Up } \\
\text { Seashore }\end{array}$ \\
\hline Hail & & & $\begin{array}{c}2085.7 * \\
(804.2)\end{array}$ & $\begin{array}{c}2020.1^{*} \\
(805.9)\end{array}$ & & \\
\hline Snowfall & & & $\begin{array}{c}-2358.4^{*} \\
(1077.0)\end{array}$ & $\begin{array}{c}-3049.8^{* * *} \\
(1025.2)\end{array}$ & & \\
\hline Precipitation (in $0.1 \mathrm{~mm}$ ) & $\begin{array}{c}-3.0^{*} \\
(1.3)\end{array}$ & $\begin{array}{c}-2.9^{*} \\
(1.3)\end{array}$ & $\begin{array}{c}-13.4^{* *} \\
(3.9)\end{array}$ & $\begin{array}{c}-11.6^{* * *} \\
(3.5)\end{array}$ & & \\
\hline Precipitation (dummy variable) & & & & & $\begin{array}{c}-437.2 * * \\
(89.1)\end{array}$ & $\begin{array}{c}-308.1^{* *} \\
(105.9)\end{array}$ \\
\hline Cloudiness (mean) & $\begin{array}{c}-57.3^{*} \\
(28.6)\end{array}$ & $\begin{array}{c}-55.4 * \\
(26.7)\end{array}$ & & & $\begin{array}{c}-152.1 * * \\
(21.2)\end{array}$ & $\begin{array}{c}-217.2^{* * *} \\
(26.5)\end{array}$ \\
\hline Temperature (max) & $\begin{array}{l}84.2^{* *} \\
(8.1)\end{array}$ & $\begin{array}{l}84.0 * * \\
(7.4)\end{array}$ & $\begin{array}{l}106.7 * * \\
(26.9)\end{array}$ & $\begin{array}{c}93.3 * * \\
(25.8)\end{array}$ & $\begin{array}{c}129.4 * * \\
(7.3)\end{array}$ & $\begin{array}{c}148.5^{* *} \\
(8.7)\end{array}$ \\
\hline Wind speed (max) & $\begin{array}{c}-55.0^{*} \\
(23.1)\end{array}$ & $\begin{array}{c}-66.2 * * \\
(21.3)\end{array}$ & $\begin{array}{c}-170.1^{* *} \\
(59.7)\end{array}$ & $\begin{array}{r}-126.4^{*} \\
(54.6)\end{array}$ & $\begin{array}{c}-49.3 * * \\
(13.9)\end{array}$ & $\begin{array}{c}-62.3 * * \\
(17.0)\end{array}$ \\
\hline Sunshine duration & & & $\begin{array}{r}1.5^{*} \\
(0.7)\end{array}$ & $\begin{array}{l}1.9 * * \\
(0.7)\end{array}$ & & \\
\hline Reduced visibility (<200 m) & & & & & $\begin{array}{c}615.0^{*} \\
(278.6)\end{array}$ & $\begin{array}{l}642.5^{* *} \\
(220.3)\end{array}$ \\
\hline$R$-squared & 0.79 & 0.69 & 0.86 & 0.85 & 0.65 & 0.67 \\
\hline
\end{tabular}

* Indicates $p$ value $<0.05$.

** Indicates $p$ value $<0.01, n=731$.

this overall model are provided in Table 5. Note that only significant location dummy interactions were included in the final models to overcome the problem of multicollinearity. Since relative traffic intensity numbers were modeled instead of absolute numbers, the parameter estimates can be directly interpreted as the percentage of change in traffic intensity. When it snows, for instance, traffic intensity will on average be $3.8 \%$ lower than during nonsnow weather.

\section{b. Dependence of weather conditions on road usage}

A first indication that the effects of various weather conditions differ among highways with divergent road uses is the clearly higher correlations (in absolute terms) between weather events and traffic intensity on the seashore highway when compared to the other locations. In contrast to these differences between locations, weather impacts are quite homogeneous when downstream and upstream (denoted as "down" and "up") intensities of the same locations are compared.

A similar conclusion can be drawn after investigation of the parameter estimates of the location-specific models: the impact of weather conditions is clearly more homogeneous (size of the effect and similar significant weather variables) between upstream and downstream traffic at a specific location, than between different locations. The heterogeneity (different effect sizes and different significant weather variables) between different locations can be (partially) explained by the underlying travel motives of the drivers using these highways. Highways typically used for leisure traffic can be affected more easily than highways that are predominantly used by commuters. We suspect that the underlying reason is that work activities are mandatory activities that cannot be easily skipped compared to the flexibility of leisure activities. That is, leisure activities are not mandatory and thus plans can be changed more freely under adverse weather conditions.

The hypothesis that alterations in road usage due to weather conditions is dependent on the purpose of the travel is substantiated by the significant interaction terms in the model between location and temperature on the

TABLE 5. Parameter estimates (HAC) for the overall model.

\begin{tabular}{lrcc}
\hline \multicolumn{1}{c}{ Weather condition } & Estimate & Standard error & Value \\
\hline Hail & 2.734 & 0.831 & $* *$ \\
Snowfall & -3.822 & 0.945 & $* *$ \\
Precipitation & -0.019 & 0.004 & $* *$ \\
Wind speed (max) & -0.418 & 0.062 & $* *$ \\
Cloudiness (mean) & -1.639 & 0.160 & $* *$ \\
Cloudiness (mean): Hasselt & 1.403 & 0.220 & $* *$ \\
Cloudiness (mean): Brussels & 1.500 & 0.208 & $* *$ \\
Cloudiness (mean): Seashore & 0.000 & $*$ & $*$ \\
Temperature (max) & 1.034 & 0.071 & $* *$ \\
Temperature (max): Hasselt & -0.619 & 0.090 & $* *$ \\
Temperature (max): Brussels & -0.792 & 0.092 & $* *$ \\
Temperature (max): Seashore & 0.000 & $*$ & $*$ \\
\hline
\end{tabular}

* Not applicable (seashore location used as reference category). ** Indicates $p$ value $<0.01, n=4386$. 
one hand, and between location and cloudiness on the other hand. This suggests that policymakers should formulate local traffic management strategies as well as countrywide strategies.

\section{Conclusions and further research}

In this study the impact of various weather conditions on traffic intensity was investigated. The most important result for policymakers is the heterogeneity of weather effects betweendifferent traffic count locations, and the homogeneity of the weather effects on upstream and downstream traffic at specific locations. Consequentially, traffic management strategies to minimize weather-related impacts on traffic operations must take local usage and the flexibility of drivers to respond to weather conditions into account

Precipitation, cloudiness, and wind speed reduce traffic intensity, and high temperatures and hail significantly increase traffic intensity. These impacts underline the necessity of incorporating weather conditions in future traffic safety research both directly and indirection. The relationship between traffic intensity, weather, and traffic safety discussed here supports the recommendation to develop location-specific traffic safety policies next to a countrywide strategy.

Further generalizations of the findings are possible by studying weather effects on local roads and by shifting the scope toward travel behavior. Moreover, further research should also encompass other factors affecting traffic intensity to isolate the effects of weather conditions and validate the findings reported in this study. Linking research on travel behavior, traffic flow (traffic intensity) modeling, and safety research by simultaneously modeling weather conditions, traffic intensity rates, collision risk, and activity travel behavior is a challenge for further research.

Acknowledgments. The authors thank the Vlaams Verkeerscentrum (Flemish Traffic Control Center) for providing the traffic count data used in this study. In addition, the authors thank the editor and reviewers for their useful comments.

\section{APPENDIX}

\section{Newey-West Heteroskedasticity and Autocorrelation Consistent Covariance Matrices}

The Newey-West covariance matrix estimator is given by

$$
\hat{\mathbf{\Sigma}}_{\mathbf{N W}}=\left(\mathbf{X}^{\prime} \mathbf{X}\right)^{-1} \hat{\mathbf{\Omega}}\left(\mathbf{X}^{\prime} \mathbf{X}\right)^{-1},
$$

where the estimated error variance $(\hat{\mathbf{\Omega}})$ is defined as

$$
\begin{aligned}
\hat{\mathbf{\Omega}}= & \frac{N}{N-k}\left\{\sum_{i=1}^{N} e_{i}^{2} x_{i} x_{i}^{\prime}+\sum_{v=1}^{q}\left[\left(1-\frac{v}{q+1}\right)\right.\right. \\
& \left.\left.\times \sum_{i=v+1}^{N}\left(x_{i} e_{i} e_{i-v} x_{i-v}^{\prime}+x_{i-v} e_{i-v} e_{i} x_{i}^{\prime}\right)\right]\right\},
\end{aligned}
$$

with $N$ as the number of observations, $k$ as the number of regressions, $e_{i}$ as the least squares residual, and $q$ as the number of truncation lags representing the number of autocorrelations used in evaluating the dynamics of the ordinary least squares residuals $e_{i}$ (Newey and West 1987) and $v$, an indicator variable for the truncation lag. Note that the use of HAC covariance matrices does not change the point estimates of the parameters, but only the estimated standard errors (Zeileis 2004).

\section{REFERENCES}

Agarwal, M., T. H. Maze, and R. Souleyrette, 2006: The weather and its impact on urban freeway traffic operations. Proc. 85th Annual Meeting of the Transportation Research Board, Washington, DC, Transportation Research Board of the National Academies, 06-1439.

Bos, J. M. J., 2001: Door weer en wind: Gevolgen van perioden met extreme weer voor de verkeersveiligheid. R-2001-23, Stichting Wetenschappelijk Onderzoek Verkeersveiligheid (SWOV), Leidschendam, Netherlands, 34 pp.

Chen, C., J. Kwon, J. Rice, A. Skabardonis, and P. Varaiya, 2003: Detecting errors and imputing missing data for single-loop surveillance systems. Transp. Res. Rec., 1855, $160-167$

Cohen, J., and P. Cohen, 1983: Applied Multiple Regression/ Correlation Analysis for the Behavioral Sciences. 2nd ed. Erlbaum, 736 pp.

Cools, M., E. Moons, and G. Wets, 2007: Investigating the effect of holidays on daily traffic counts: A time series approach. Transp. Res. Rec., 2019, 22-31.

Datla, S., and S. Sharma, 2008: Impact of cold and snow on temporal and spatial variations of highway traffic volumes. J. Transp. Geogr., 16, 358-372.

De Palma, A., and D. Rochat, 1999: Understanding individual travel decisions: Results from a commuters survey in Geneva. Transportation, 26, 263-281.

Edwards, J. B., 1996: Weather-related road accidents in England and Wales: A spatial analysis. J. Transp. Geogr., 4, 201-212.

Fridstrøm, L., J. Ifver, S. Ingebrigtsen, R. Kulmala, and L. K. Thomsen, 1995: Measuring the contribution of randomness, exposure, weather, and daylight to the variation in road accident counts. Accid. Anal. Prev., 27, 1-20.

Golob, T. F., W. W. Recker, and V. M. Alvarez, 2004: Freeway safety as a function of traffic flow. Accid. Anal. Prev., 36, 933-946.

Guo, Z., N. H. M. Wilson, and A. Rahbee, 2007: Impact of weather on transit ridership in Chicago, Illinois. Transp. Res. Rec., 2034, 3-10. 
Hanbali, R. M., and D. A. Kuemmel, 1993: Traffic volume reductions due to winter storm conditions. Transp. Res. Rec., 1387, 159-164.

Hassan, Y. A., and D. J. Barker, 1999: The impact of unseasonable or extreme weather on traffic activity within Lothian region, Scotland. J. Transp. Geogr., 7, 209-213.

Hranac, R., E. Sterzin, D. Krechmer, H. Rahka, and M. Farzaneh, 2006: Empirical studies on traffic flow in inclement weather. Rep. FHWA-HOP-07-073, Federal Highway Administration, U.S. Department of Transportation, Washington, DC, 114 pp.

Ibrahim, A. T., and F. L. Hall, 1994: Effect of adverse weather conditions on speed-flow-occupancy relationships. Transp. Res. Rec., 1457, 184-191.

Keay, K., and I. Simmonds, 2005: The association of rainfall and other weather variables with road traffic volume in Melbourne, Australia. Accid. Anal. Prev., 37, 109-124.

Khattak, A. J., and A. De Palma, 1997: The impact of adverse weather conditions on the propensity to change travel decisions: A survey of Brussels commuters. Transp. Res. Part A Policy Pract., 31, 181-203.

Koetse, M. J., and P. Rietveld, 2007: Climate change, adverse weather conditions, and transport: A literature survey. Proc. Ninth Nectar Conf., Porto, Portugal, Network on European Communication and Transportation Activities Research (NECTAR), 75.

Kyte, M., Z. Khatib, P. Shannon, and F. Kitchener, 2001: Effect of weather on free-flow speed. Transp. Res. Rec., 1776, 60-68.

Levine, N., K. E. Kim, and L. H. Nitz, 1995: Daily fluctuations in Honolulu motor vehicle accidents. Accid. Anal. Prev., 27, 785-796.

Maerivoet, S., 2006: Modeling traffic on motorways: State-of-theart, numerical data analysis, and dynamic traffic assignment. $\mathrm{Ph} . \mathrm{D}$. dissertation, Katholieke Universiteit Leuven, 458 pp.

Maze, T. H., M. Agarwal, and G. Burchett, 2006: Whether weather matters to traffic demand, traffic safety, and traffic operations and flow. Transp. Res. Rec., 1948, 170-176.

Nankervis, M., 1999: The effect of weather and climate on bicycle commuting. Transp. Res. Part A Policy Pract., 33, 417-431.

Neter, J., M. H. Kutner, C. J. Nachtsheim, and W. Wasserman, 1996: Applied Linear Statistical Models. 2nd ed. McGraw-Hill, 1265 pp.
Newey, W., and K. West, 1987: A simple positive semi-definite, heteroskedasticity and autocorrelation consistent covariance matrix. Econometrica, 55, 703-708.

Shankar, V. N., S. Chayanan, S. Sittikariya, M.-B. Shyu, N. K. Juvva, and J. C. Milton, 2004: Marginal impacts of design, traffic, weather, and related interactions on roadside crashes. Transp. Res. Rec., 1897, 156-163.

Smith, B. L., K. G. Byrne, R. B. Copperman, S. M. Hennessy, and N. J. Goodall, 2004: An investigation into the impact of rainfall on freeway traffic flow. Proc. 83rd Annual Meeting of the Transportation Research Board, Washington, DC, Transportation Research Board of the National Academies, TRB2004-000760.

Stern, A., V. Shah, L. Goodwin, and P. Pisano, 2003: Analysis of weather impacts on traffic flow in metropolitan Washington DC. Preprints, 19th Int. Conf. on Interactive Information and Processing Systems (IIPS) for Meteorology, Oceanography, and Hydrology, Long Beach, CA, Amer. Meteor. Soc., 10.3 .

Unrau, D., and J. Andrey, 2006: Driver response to rainfall on urban expressways. Transp. Res. Rec., 1980, 24-30.

Van den Bossche, F., G. Wets, and T. Brijs, 2004: A regression model with ARMA errors to investigate the frequency and severity of road traffic accidents. Proc. 83rd Annual Meeting of the Transportation Research Board, Washington, DC, Transportation Research Board of the National Academies, TRB2004-001658.

- - — road accidents: A Belgian case study. Transp. Res. Rec., 1908, 96-103.

Weijermars, W., and E. Van Berkum, 2006: Detection of invalid loop detector data in urban areas. Transp. Res. Rec., 1945, $82-88$.

Zeileis, A., 2004: Econometric computing with $\mathrm{HC}$ and HAC covariance matrix estimators. J. Stat. Softw., 11, 1-17.

Zhang, L., J. Colyar, P. Pisano, and P. Holm, 2005: Identifying and assessing key weather-related parameters and their impacts on traffic operations using simulation. Proc. 84th Annual Meeting of the Transportation Research Board, Washington, DC, Transportation Research Board of the National Academies, 05-0962. 